Article

\title{
The Impact of Foreign Aid on Maternal Mortality
}

\author{
Emmanuel Banchani and Liam Swiss * \\ Department of Sociology, Memorial University of Newfoundland, St. John's, A1C 5S7, Canada; \\ E-Mails: eb1043@mun.ca (E.B.), Iswiss@mun.ca (L.S.) \\ * Corresponding author
}

Submitted: 19 November 2018 | Accepted: 12 April 2019 | Published: 5 June 2019

\begin{abstract}
In 2010, the G8 placed renewed focus on maternal health via the Muskoka Initiative by committing to spend an additional $\$ 5$ billion on maternal, newborn, and child health before 2015. Following the end of the Millennium Development Goals and the advent of the Sustainable Development Goals, maternal health issues have continued to feature prominently on the global health agenda. Despite these substantial investments of foreign aid over the past decade, there is limited evidence on the effectiveness of foreign aid in reducing maternal mortality in low- and middle-income countries (LMICs). Using data from the Organisation for Economic Cooperation and Development, the World Development Indicators and the Institute of Health Metrics and Evaluation, this study analyzes the effects of aid on maternal health in a sample of 130 LMICs from 1996 through 2015. Our results show that the effects of total foreign aid on maternal mortality are limited, but that aid allocated to the reproductive health sector and directly at maternal health is associated with significant reductions in maternal mortality. Given these targeted effects, it is important to channel more donor assistance to the promotion of reproductive health and contraceptive use among women as it serves as a tool towards the reduction of maternal mortality.
\end{abstract}

\section{Keywords}

family planning; foreign aid; maternal mortality; Muskoka Initiative; reproductive health

\section{Issue}

This article is part of the issue "Aid Impact and Effectiveness", edited by Rachel M. Gisselquist and Finn Tarp (UNU-WIDER, Finland).

(C) 2019 by UNU-WIDER; licensee Cogitatio (Lisbon, Portugal). This article is licensed under a Creative Commons Attribution 4.0 International License (CC BY).

\section{Introduction}

Recent debates concerning the effectiveness of aid in improving development outcomes have been inconclusive (Tilburg, 2015). Aid critics (Easterly, 2006; Moyo, 2009; Winters, 2010) have voiced their concerns that aid is "dead". They maintain that billions of dollars have been transferred to poor economies with the aim of improving living conditions, but the results have always been catastrophic, leaving more than a billion people still living in abject poverty. Despite these concerted efforts, there has been limited academic research on the links between foreign aid and maternal mortality reduction in low- and middle-income countries (LMICs; Taylor, Hayman, Crawford, Jeffery, \& Smith, 2013).
In the case aid committed to maternal health, the Muskoka Initiative on Maternal, Newborn and Child Health was one such commitment adopted at the G8 summit in 2010. This initiative saw a commitment of $\$ 7.3$ billion through 2015 to improve maternal and child health in the world's poorest countries and to contribute to the achievement of Goal 5 of the Millennium Development Goals (MDGs). The presumption that aid can combat maternal mortality, however, seemed to be based on limited evidence, and this relationship has rarely featured in the global health research agenda.

Given the Muskoka commitments, and support for the MDGs and Sustainable Development Goals (SDGs), over the past decade, the donor community has committed sizeable financial resources to the reduction of 
maternal deaths in developing countries. Between 1990 and 2017 and estimated \$11.6 billion has been invested in maternal health (Institute of Health Metrics and Evaluation [IHME], 2018). Yet, high levels of maternal mortality are still prevalent in many parts of the world. It is estimated that in 2015 99\% $(302,000)$ of maternal deaths were recorded in LMICs compared to other developed regions of the world (World Health Organization [WHO], UNICEF, UNFPA, \& The World Bank, 2015). Given the seeming role for international development assistance in combatting this development challenge, it is important to assess the evidence of aid's efficacy in reducing maternal mortality. As such, this study examines the effect of foreign aid on maternal mortality in LMICs using two-way fixed effects panel regression over the period from 1996 through 2015.

\section{Background}

Evidence suggests most LMICs were not able to meet the targets of the health-related MDGs of reducing maternal mortality ratio by 75\% between 1990 and 2015 (WHO et al., 2015). Indeed, by 2015 , the WHO reported an estimated decline in global maternal mortality rate (MMR) of $45 \%$ in that period to 210 deaths per 100,0000 live births, far short of the $75 \%$ reduction goal. Following the MDGs, the SDGs set a target of lowering MMR to 70 per 100,000 live births, as part of SDG 3's goal to "ensure healthy lives and promote wellbeing for all at all ages". To this end, several donor countries have pledged their support to increase funding towards the reduction of maternal health levels to the countries with the poorest health indicators (Proulx, Ruckert, \& Labonté, 2017).

Previous foreign aid research has mainly focused on economic development and poverty reduction with mixed results. For example, Bornschier, Chase-Dunn and Robinson (1978), Dalgaard, Hansen and Tarp (2004), and Arndt, Jones and Tarp (2015) all show that foreign aid has a positive impact on economic growth. In contrast, Durbarry, Gemmel and Greenaway (1998), and Annen and Kosempel (2009) and Easterly (2003) show that foreign aid has no impact on economic growth. Ekanayake, Cookman and Chatrna's (2000) study on the effect of foreign aid in developing countries show that there is no impact. Given the complex relationship between health and development, there is an interest in exploring how investments in people's overall health in a country contribute to economic development. It is argued that if the productive workforce is healthy, they can work meaningfully towards higher productivity translating into a higher economic growth and development.

While these studies provide an important step in obtaining empirical evidence of the role of foreign aid on development outcomes, few studies to date have examined the impact of foreign aid on health outcomes such as mortality (Kotsadam, $\varnothing$ stby, Rustad, Tollefsen, \& Urdal, 2018). Early studies point to a harmful effect of aid on mortality and health outcomes, specifically in the case where aid increased the indebtedness of recipient countries (Bradshaw, Noonan, Gash, \& Sershen, 1993; Sell \& Kunitz, 1986). Shen and Williamson (1999) find that greater indebtedness-in some cases aid-relatedindirectly increases maternal mortality, but conclude their study with a rallying call to donors, arguing: "It is likely that even a modest increase in aid could substantially improve maternal mortality rates if it were spent on improving the access of poor women to health services" (p. 211).

More recent studies on the impact of foreign aid on mortality have mainly focused on infant or child mortality (Burguet \& Soto, 2012; Kotsadam et al., 2018; Mishra \& Newhouse, 2009; Pandolfelli, Shandra, \& Tyagi, 2014; Winkleman \& Adams, 2017). Similarly to the economic literature, empirical evidence suggests that the effects of foreign aid on mortality are inconclusive. Many studies highlight the inefficacy or negative effects of aid. For example, Williamson (2008) find that foreign aid is ineffective in improving overall health. Likewise, Pandolfelli et al. (2014) find that International Monetary Fund loans and structural adjustment contribute to higher maternal mortality in Sub-Saharan Africa. These deleterious effects of structural adjustment on child and maternal mortality are echoed by Thomson, Kentikelenis and Stubbs (2017), Powell-Johnson, Borghi, Mueller, Patouillard and Mills (2006) also find a positive relationship between mortality and Official Development Assistance (ODA). Other research is mixed: Mishra and Newhouse (2009) show that total overall aid had no impact on infant mortality, while health aid reduced mortality levels. Still other studies find beneficial effects of aid on mortality rates: Kotsadam et al. (2018) show that aid programming reduces infant mortality for marginalized communities, while Yogo and Mallaye (2015) demonstrate that increased health aid is linked to significant decreases in child mortality.

While few studies have touched on aid's effect on maternal mortality, there has been a concerted effort to track aid spending in this area. Greco, Powell-Jackson, Borghi and Mills (2008) tracked the flow of health-related aid from 2003 through 2006 and found that aid to maternal health did not always go to the most affected countries. This tracking was part of a series of Lancet articles which mapped ODA spending on maternal health but did not analyze its effects on maternal mortality (Arregoces et al., 2015; Grollman et al., 2017; Hsu, Pitt, Greco, Berman, \& Mills, 2012; Powell-Johnson et al., 2006). These studies provide a strong basis upon which to examine the effects of the flow of aid to maternal health.

Considering the significant international attention paid to the maternal mortality issue by the international community and donor agencies in recent years, the relative absence of empirical evidence linking aid and reduced mortality is surprising. This study aims to provide some of this evidence and examine the impact of several categories of foreign aid spending on maternal mortality over time. This evidence is important, not only to better understand the health effects of aid, but also to ex- 
pand the growing literatures linking aid to gender equality outcomes (Grown, Addison, \& Tarp, 2016; Pickbourn \& Ndikumana, 2016; Tiessen, 2015).

\section{Data and Methods}

\subsection{Data}

Data for this study are drawn from the Organisation for Economic Cooperation and Development (OECD) Creditor Reporting System (CRS) database, the World Development Indicators (WDI) from the World Bank, the IHME database, and Grollman et al.'s (2017) ODA + data set on aid to maternal health.

Our main sample consists of 130 LMICs that were eligible to receive the various categories of aid between 1996 and 2015. In total, the sample consists of 2,093 country-year observations over that period for which all data was available. Descriptive statistics for our sample are shown in Table 1.

The dependent variable in this study is MMR: the number of maternal deaths in a given period per 100,000 women of reproductive age during the same time pe- riod (WHO, UNICEF, UNFPA, \& The World Bank, 2012). We test the relationship between aid and MMR using two different data sources for the dependent variable. The MMR measure in our main analysis consists of MMR data from the WHO and housed in the World Bank's WDI dataset. As a robustness check, we also repeat our analysis using MMR data from the IHME "Maternal Mortality Estimates and MDG 5 Attainment by Country 1990-2011" dataset (IHME, 2011). The WHO defines maternal death as:

The death of a woman while pregnant or within 42 days of termination of pregnancy, irrespective of the duration and site of pregnancy from any cause related to or aggravated by the pregnancy or its management but not from accidental or incidental causes. (WHO ICD-10, 2011, p. 156)

The causes of maternal death according to the WHO can be direct or indirect causes. The direct causes are those resulting from complications of the pregnant state, from interventions, omissions, incorrect treatment, or from a chain of events resulting from any of the above.

Table 1. Sample descriptive statistics, 130 countries, 1996-2015.

\begin{tabular}{|c|c|c|c|c|c|c|c|}
\hline & Min & Mean & Median & Max & SD & $\mathbf{N}$ & Source \\
\hline \multicolumn{8}{|l|}{ Dependent variable } \\
\hline $\begin{array}{l}\text { Maternal mortality ratio (MMR)-primary } \\
\text { analysis }\end{array}$ & 4.00 & 289.32 & 148.00 & 2650.00 & 321.69 & 2093 & WDI \\
\hline $\begin{array}{l}\text { Maternal mortality ratio (MMR)-robustness } \\
\text { analysis }\end{array}$ & 6.80 & 294.00 & 113.50 & 2592.50 & 335.29 & 1709 & IHME \\
\hline \multicolumn{8}{|l|}{ Aid measures (per capita) } \\
\hline Total aid (constant 2011 USD) & 0.00 & 68.66 & 39.95 & 1257.09 & 98.73 & 2093 & OECD CRS \\
\hline Total aid to Health (constant 2011 USD) & 0.00 & 4.14 & 1.57 & 170.19 & 8.94 & 2093 & OECD CRS \\
\hline $\begin{array}{l}\text { Total population/reproductive policy and } \\
\text { programming (constant } 2011 \text { USD) }\end{array}$ & 0.00 & 2.87 & 0.80 & 133.76 & 7.56 & 2093 & OECD CRS \\
\hline $\begin{array}{l}\text { Aid to reproductive health } \\
\text { (constant } 2011 \text { USD) }\end{array}$ & 0.00 & 0.34 & 0.09 & 11.83 & 0.76 & 2093 & OECD CRS \\
\hline Aid to family planning (constant 2011 USD) & 0.00 & 0.16 & 0.00 & 5.75 & 0.41 & 2093 & OECD CRS \\
\hline $\begin{array}{l}\text { Total maternal and newborn health aid } \\
\text { (constant } 2013 \text { USD) }\end{array}$ & 0.00 & 0.57 & 0.09 & 12.36 & 1.10 & 2093 & $\begin{array}{l}\text { Grollman } \\
\text { et al., } 2017\end{array}$ \\
\hline \multicolumn{8}{|l|}{ Controls } \\
\hline GDP per capita, (constant 2010 USD) & 186.66 & 5414.95 & 2357.40 & 72670.96 & 9666.15 & 2093 & WDI \\
\hline $\begin{array}{l}\text { Births attended by skilled health personnel, } \\
\text { percentage, percent }\end{array}$ & 5.60 & 72.28 & 81.00 & 100.00 & 27.06 & 2093 & WDI \\
\hline $\begin{array}{l}\text { Adolescent fertility rate (births per } \\
1,000 \text { women ages } 15-19)\end{array}$ & 3.82 & 72.17 & 63.98 & 218.77 & 47.62 & 2093 & WDI \\
\hline $\begin{array}{l}\text { Contraceptive prevalence, modern methods } \\
\text { (percent of women ages 15-49) }\end{array}$ & 1.20 & 35.76 & 34.50 & 86.20 & 20.92 & 2093 & WDI \\
\hline \multicolumn{8}{|l|}{ Instrument } \\
\hline $\begin{array}{l}\text { Donor fractionalization-recipient aid } \\
\text { probability interaction }\end{array}$ & 0 & 0.22 & 0.25 & 0.38 & 0.08 & 2055 & $\begin{array}{l}\text { OECD/ } \\
\text { WB DPI }\end{array}$ \\
\hline
\end{tabular}


The indirect causes are those not due to direct obstetric causes. Not surprisingly, there is a close association between economic development in a country and its rates of maternal mortality. Figure 1 highlights this relationship for our sample countries in 2015, showing that wealthier countries are likely to have lower rates of mortality. Mean MMR in our sample is approximately 289 deaths per 100,000 women, while median MMR is approximately 148 . MMR varies significantly across different geographic regions within our sample and over time. Figure 2 shows this variability, revealing that over- all MMR has declined significantly over time, but remains high in certain regions.

Our main independent variables are the annual ODA flows for six categories of aid in millions of constant 2011 USD. The source from the OECD is the net bilateral ODA commitments by the Development Assistance Committee (DAC) donors reported from the CRS. This study considers all forms of aid commitments allocated by the DAC donor countries. We consider the effects of six categories of bilateral aid: total aid, total health-related aid, total aid to population/reproduction policy and programming,

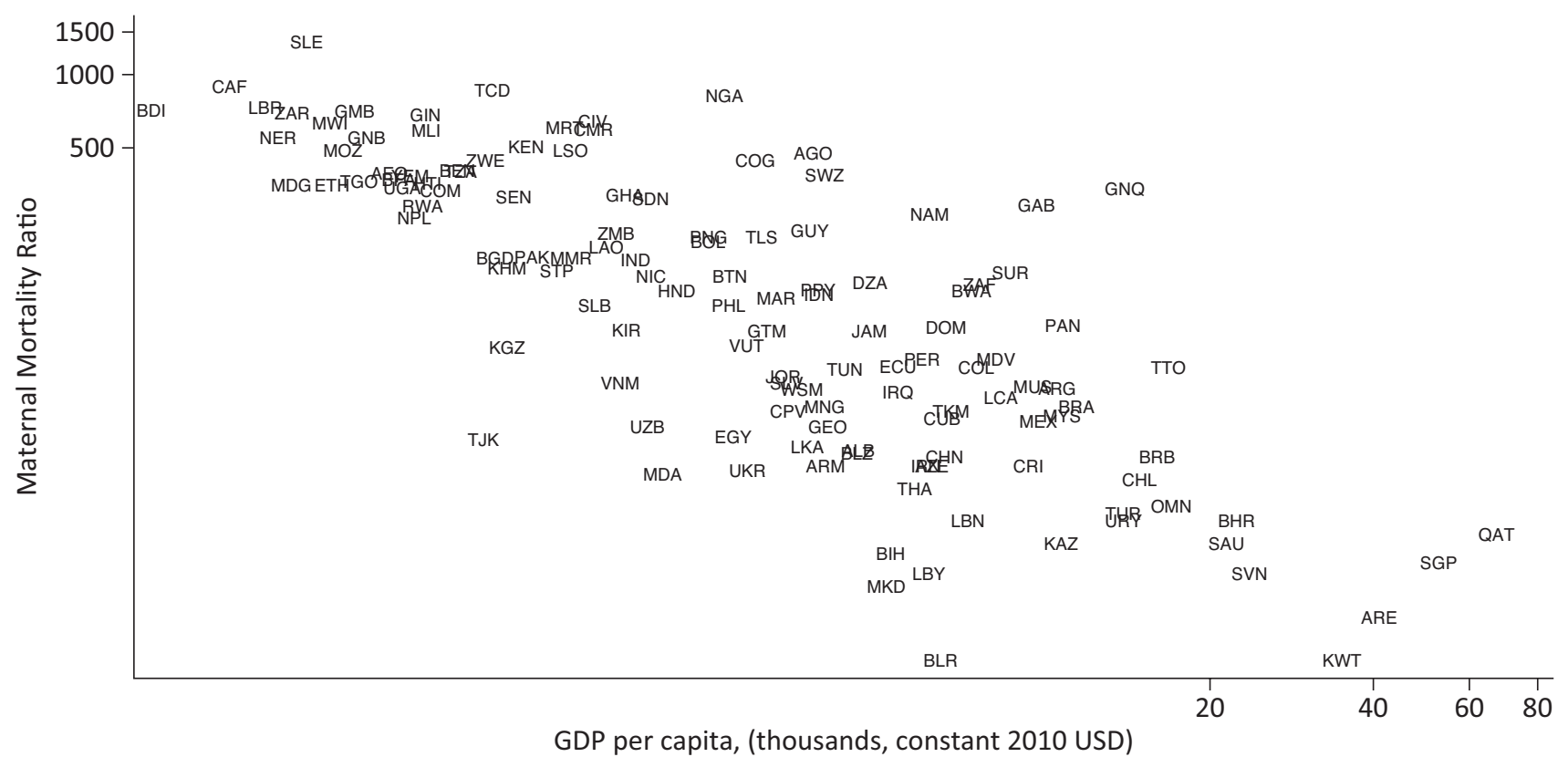

Figure 1. Relationship of sample country GDP per capita and maternal mortality, 2015.

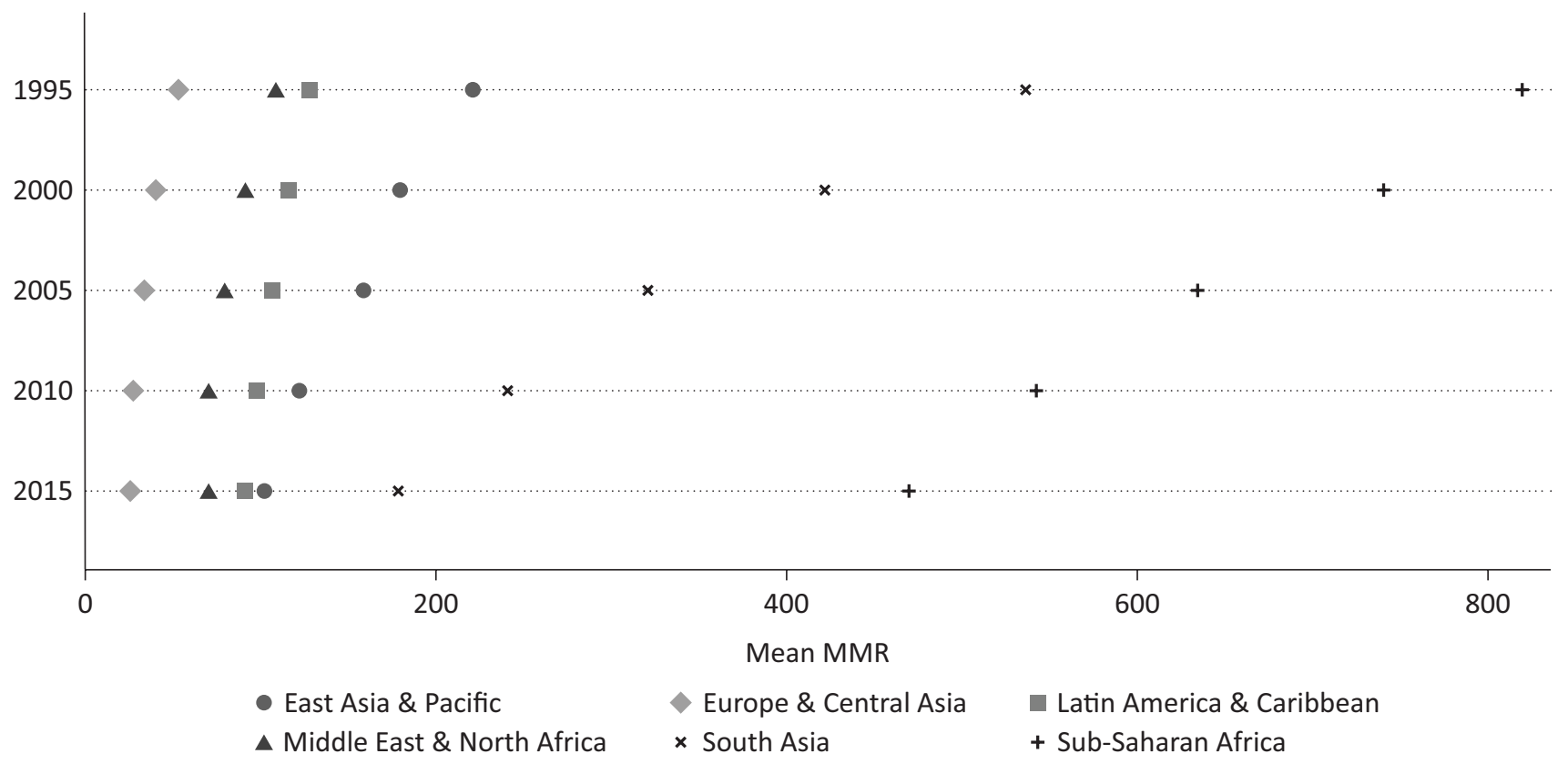

Figure 2. Mean maternal mortality ratio by region, 1995-2015. 
reproductive health aid, family planning aid, and total aid to maternal and newborn health. ${ }^{1}$ Figure 3 shows how the first five of these categories maps onto DAC aid codes. To account for variation in population size between countries, we convert these ODA data into per capita measures. Our analysis uses the log (base 2) of these measures to account for skewness, meaning that the coefficients for each measure can be interpreted as the marginal effect of a doubling of that type of aid.

Our analysis also accounts for other variables that have an impact on maternal mortality. The other variables included are Gross Domestic Product (GDP) per capita, births attended by a skilled birth attendant, adolescent fertility rate, and population using any method of contraception and the total population. Each of these variables is drawn from the World Bank's WDI databank. To address missing values in this data we replaced missing data with the most recent year's non-missing data. These independent variables are explained below.

GDP per capita: There is a strong negative correlation between a country's level of national income and maternal mortality ratio (Bishai et al., 2016). This relationship has been shown to be robust over time and is evident in Figure 1. Mean GDP per capita in our sample is $\$ 5415$. In our models, GDP per capita is measured in constant 2010 US dollars and is logged to account for skewness.

Skilled birth attendant: According to a statement by WHO, International Confederation of Midwives (ICM), and the International Federation of Gynecology and Obstetrics (FIGO), the term 'skilled attendant' refers to:

An accredited health professional-such as midwife, doctor or nurse-who has been educated and trained to proficiency in the skills needed to manage normal (uncomplicated) pregnancies, childbirth and the immediate postnatal period, and in the identification, management or referral of complications in women and newborns. (WHO, ICM, \& FIGO, 2004, p. 1)

Traditional birth attendants either trained or not, are excluded from this category of skilled health workers (WHO et al., 2004 as cited in Nanda, Switlick, \& Lule, 2005, p. 9). This measure reflects the percentage of births attended by skilled health personnel, with a mean of $72 \%$ of births in countries in our sample over time.

Adolescent fertility rate: The association between maternal mortality and the age at birth of mothers is wellestablished in the literature (Conde-Agudelo, Belizan, \& Lammers 2005; Nove, Mathews, Neal, \& Camacho, 2014; WHO, 2018). In our models, adolescent fertility is measured by the rate of births per 1,000 women aged 15-19 years, and averages 72 births per 1,000 women in our sample.

Modern contraceptive use: We account for contraceptive use in our analysis using a measure of the percentage of women ages 15-49 using at least one mod-

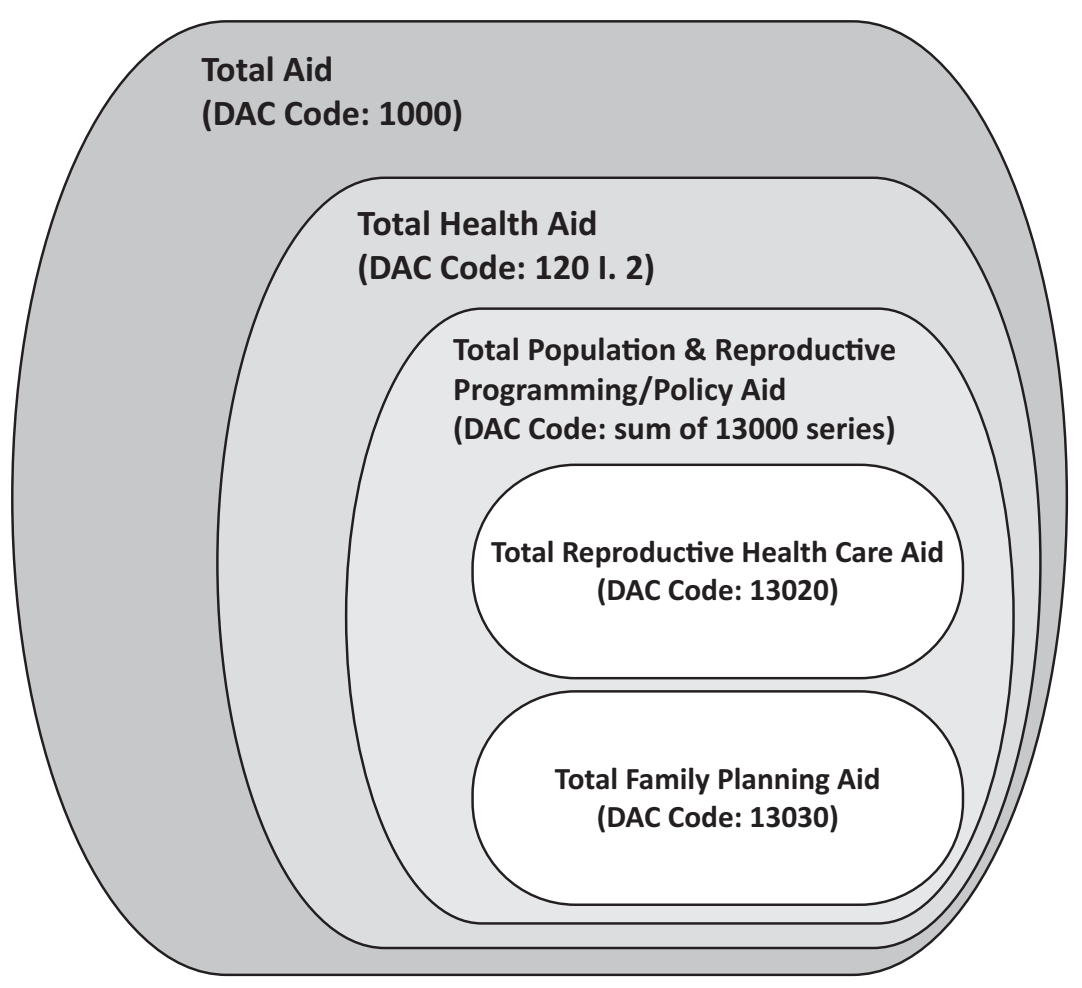

Figure 3. Aid independent variables and corresponding DAC codes.

\footnotetext{
1 The first five categories correspond to the following DAC Sector Codes in the CRS: Total Aid (1000); Health Total (120 I. 2); Total Population and Reproductive Programming and Policy (total of 13000s); Reproductive Health Care (13020); and Family Planning (13030). The final category, total aid to maternal and newborn health, is drawn from the ODA plus dataset presented in Grollman et al. (2017).
} 
ern form of birth control. In our models we use this measure to serve as a proxy measure of reproductive health services and women's empowerment (WHO, 2011). The mean of modern birth control use in our sample is approximately $34 \%$.

\subsection{Analysis}

We use a two-way fixed effects panel regression model with both year- and country-fixed effects to analyze the impact of foreign aid on maternal mortality. Including both fixed effects components in our models allows us to account for the influence of correlation within countries over time and the effect of global time trends on maternal mortality ratios and all other co-variates. As a result, our models help us predict the effect of aid on change in MMR within countries over time and control for all timeinvariant characteristics of a given country. We lag all of our independent measures one-year behind the dependent variable to allow for a temporal gap in which the effects of aid might take hold. ${ }^{2}$ For example, in our analy- sis we are predicting the effects of all independent measures in 2000 on MMR in 2001, or the effects of independent variables in 1996 on MMR in 1997. Finally, we run separate sets of nested models for each of the four aid measures because they are too highly correlated to provide meaningful results if included in a single model.

\section{Results}

We ran a series of nested models for each aid measure, but in Table 2 we present only the full models for each for the sake of parsimony. Each model includes one of our aid measures, as well as the controls for country-level characteristics. Each of the aid measures is negatively associated with MMRs, but in the case of the Total Aid measure we fail to reject the null hypothesis. The results represent the effect of a doubling of a given type of aid. The strongest effects are seen in total maternal and newborn health aid (from the ODA plus source) and in ODA committed under the reproductive health category, where a doubling predicts a more than 33 death reduction and 26

Table 2. Two-way fixed effects panel regression of maternal mortality on total foreign aid, 1996-2015.

\section{Aid measures (logged)}

Total aid

Total aid to health

Aid to reproductive health

Aid to family planning

Total aid to population/reproductive policy and programming

Total Maternal and Newborn Health Aid (ODA plus dataset)
(1)

(2)

$-7.12 * * *$
$-13.10^{*}$

\begin{tabular}{|c|c|c|c|c|c|c|}
\hline Controls & & & & & & \\
\hline $\begin{array}{l}\text { Logged GDP per capita, } \\
\text { (constant } 2010 \text { USD) }\end{array}$ & $-42.31 * * *$ & $-42.83 * * *$ & $-44.84 * * *$ & $-41.72 * * *$ & $-43.74 * * *$ & $-47.16 * * *$ \\
\hline $\begin{array}{l}\text { Births attended by skilled health } \\
\text { personnel, percentage, percent }\end{array}$ & $-1.06 * * *$ & $-1.08^{* * *}$ & $-0.93 * * *$ & $-1.04 * * *$ & $-1.10 * * *$ & $-1.03 * * *$ \\
\hline $\begin{array}{l}\text { Adolescent fertility rate (births per } \\
1,000 \text { women ages } 15-19)\end{array}$ & $3.66 * * *$ & $3.63 * * *$ & $3.53 * * *$ & $3.59 * * *$ & $3.44 * * *$ & $3.41 * * *$ \\
\hline $\begin{array}{l}\text { Contraceptive prevalence, modern } \\
\text { methods (percent of women } \\
\text { ages 15-49) }\end{array}$ & $-1.89 * * *$ & $-1.86 * * *$ & $-1.83^{* * *}$ & $-1.89 * * *$ & $-1.55^{* * *}$ & $-1.77 * * *$ \\
\hline Constant & $649.76 * * *$ & $661.10 * * *$ & $679.78 * * *$ & $644.47 * * *$ & $683.94 * * *$ & $716.45^{* * *}$ \\
\hline Observations & 2093 & 2093 & 2093 & 2093 & 2093 & 2093 \\
\hline Countries & 130 & 130 & 130 & 130 & 130 & 130 \\
\hline R-Squared & 0.70 & 0.70 & 0.69 & 0.70 & 0.69 & 0.70 \\
\hline Country FE & yes & yes & yes & yes & yes & yes \\
\hline Year FE & yes & yes & yes & yes & yes & yes \\
\hline
\end{tabular}

Notes: ${ }^{*} \mathrm{p}<0.05,{ }^{* * *} \mathrm{p}<0.001$

\footnotetext{
${ }^{2}$ We also tested 2-, 3-, 4-, and 5-year lags and the results were comparable except in the case of one aid measure. Due to the nature of our dataset, the one-year lag maximizes our sample size.
} 
death reduction in MMR respectively. These marginal effects are shown in Figure 4, and indicate that, apart from total aid's non-significant relationship to MMR, the most modest effect on MMR is for total health aid. Increases in family planning aid and total population/reproductive policy aid also predict reduced MMR.

Our controls for country and society characteristics are all correlated with MMRs at the $p<0.001$ level. A doubling of GDP per capita predicts the sharpest reduction in MMR in all models, while more modest reductions in MMR are associated with increased rates of birth attendance by skilled health professionals and contraceptive prevalence. In contrast, adolescent fertility rates are associated with increases in MMR in all models. The results of these models show that countries with growing economies, improving health systems, more readily available contraception, and decreasing teen birth rates all stand to see reductions in their national MMR over time.

When comparing our main results to those in our robustness checks included in the appendix, we note two differences worth discussing. First, with the change in sample introduced via the instruments in the instrumental variable analysis (see Appendix Table A1), via the longer lag period (see Appendix Table A2), or via the use of the IHME MMR data which is restricted to the 1996-2011 period, the robustness of our estimate for the effect of family planning related aid on MMR is challenged. In each of the robustness check models, we see that the family planning aid parameters no longer allow us to reject the null hypothesis. The second difference, seen in Tables A1 and A3, are that with the shorter timeframe and alternate specifications, the total effect of aid on MMR does meet the $p<0.05$ level in our robustness checks, suggesting that overall aid is correlated with reductions in MMR.

\subsection{Robustness Checks}

We also conducted a set robustness check models using: (1) instrumental variable models; (2) instrumental variable regressions with five-year averaged aid flows; (3) five different lag periods for our independent variables; and (4) the alternative measure of MMR from the IHME. Our first robustness check was to reanalyze our data using an instrumental variable approach (see Appendix, Table A1). Following Dreher and Langlotz (2017) and Doucouliagos, Hennessy, and Mallick (2019), we use an excludable instrument based upon the fractionalization of governments in donor countries interacted with the probability of recipient countries receiving aid in a given year. We construct this instrument measure using a dyadic donor-recipient aid dataset based on OECD figures used in Swiss and Longhofer (2016). Because foreign aid levels are endogenous to some measures of development and the other independent variables in our model, we control for endogeneity by using a two-stage approach in our instrumental variable models.

In a zero-stage regression, we use OLS to regress our various aid measures on a lag of each aid measure and the five-year lag of donor government fractionaliza-

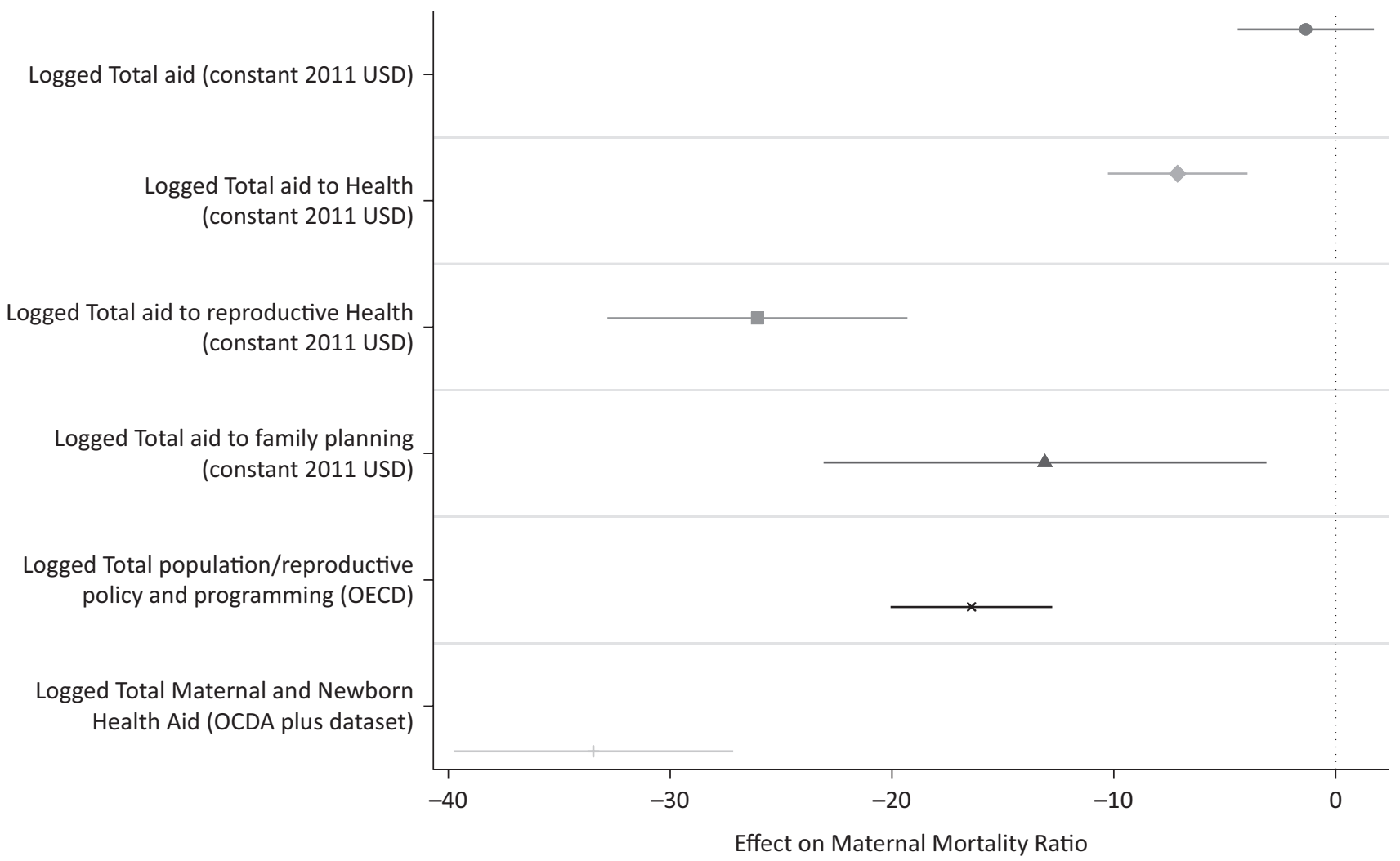

Figure 4. Marginal effect of logged aid on maternal mortality with $95 \%$ confidence intervals. 
tion interacted with the probability of the recipient country receiving aid from all donors. Because aid levels are closely linked to government competition within donor states (Dreher \& Langlotz, 2017), this instrument the level of global aid is fluctuates independently of the conditions in recipient countries. Following this zero-stage model, we predict a fitted aid measure that serves as the excludable instrument in the first-stage model. By interacting the mean donor fractionalization with the mean probability of each recipient country to receive aid from all donors in a given year, the instrument remains exogenous to the MMR variable in the second stage.

In the two-stage IV regression, the aid measure is instrumented on the fitted aid predicted in the zero-stage models. The IV models also include year and country fixed-effects. The results of the IV models in Table A1 show a similar pattern to our main results below.

The second robustness check tested an alternate specification of our aid measures using a five-year moving average (see Appendix, Table A2). These results are consistent with our main analysis, but with the five-year averages, each of the predicted aid measures is associated with reductions in maternal mortality.

Our third robustness check tested the effect of different lag periods between our dependent and independent variables (see Appendix, Table A2). These results are consistent with our main analysis, but with a longer lag period, the predicted effects of family planning aid no longer attain $p$-values below the commonly accepted 0.5 threshold.

Our final robustness check was to repeat our analysis using the alternative MMR measure discussed earlier (see Appendix, Table A3). These results closely echo our main analysis but, as in the case of Table $A 1$, there are some minor differences of note.

\section{Discussion}

Our findings show clearly that aid-depending on the sector in which it is spent-has the potential to help reduce maternal mortality. As Figure 3 highlights, the effects of reproductive health-focused aid or aid targeted specifically at maternal health are stronger than that of total aid or total health aid. Given the narrowed focus of reproductive health-focused aid, it is not unexpected it might reduce maternal mortality more directly. If, for instance, reproductive health aid is specifically channeled to the promotion of prenatal and postnatal care including deliveries (which are crucial in elements in the reduction of maternal mortality), an increase in reproductive health aid will have a greater likelihood of diminishing MMR.

With an equally narrow focus as reproductive healthrelated aid, what might explain the counterintuitive finding we see in the mixed effects of family planningfocused aid between our main analysis and the robustness checks? Comparing the relationship between reproductive health aid and family planning aid in Figure 5 reveals relatively low correlation between the two types of aid (Pearson's R of 0.28 in our sample). This suggests that the same countries receiving significant amounts of reproductive health aid are not necessarily also in receipt of family planning aid and vice versa. Likewise, the bivariate relationship of family planning aid to each of adolescent fertility, birth control, and MMR reveal very low levels of correlation $<0.1$ in each case. This implies that, regardless of the intent of family planning-related aid to make contraceptives more widely available, these programs are not necessarily associated with reducing MMR either directly or indirectly through reduced fertility or contraceptive use. Cleland et al. (2006) suggest that un-

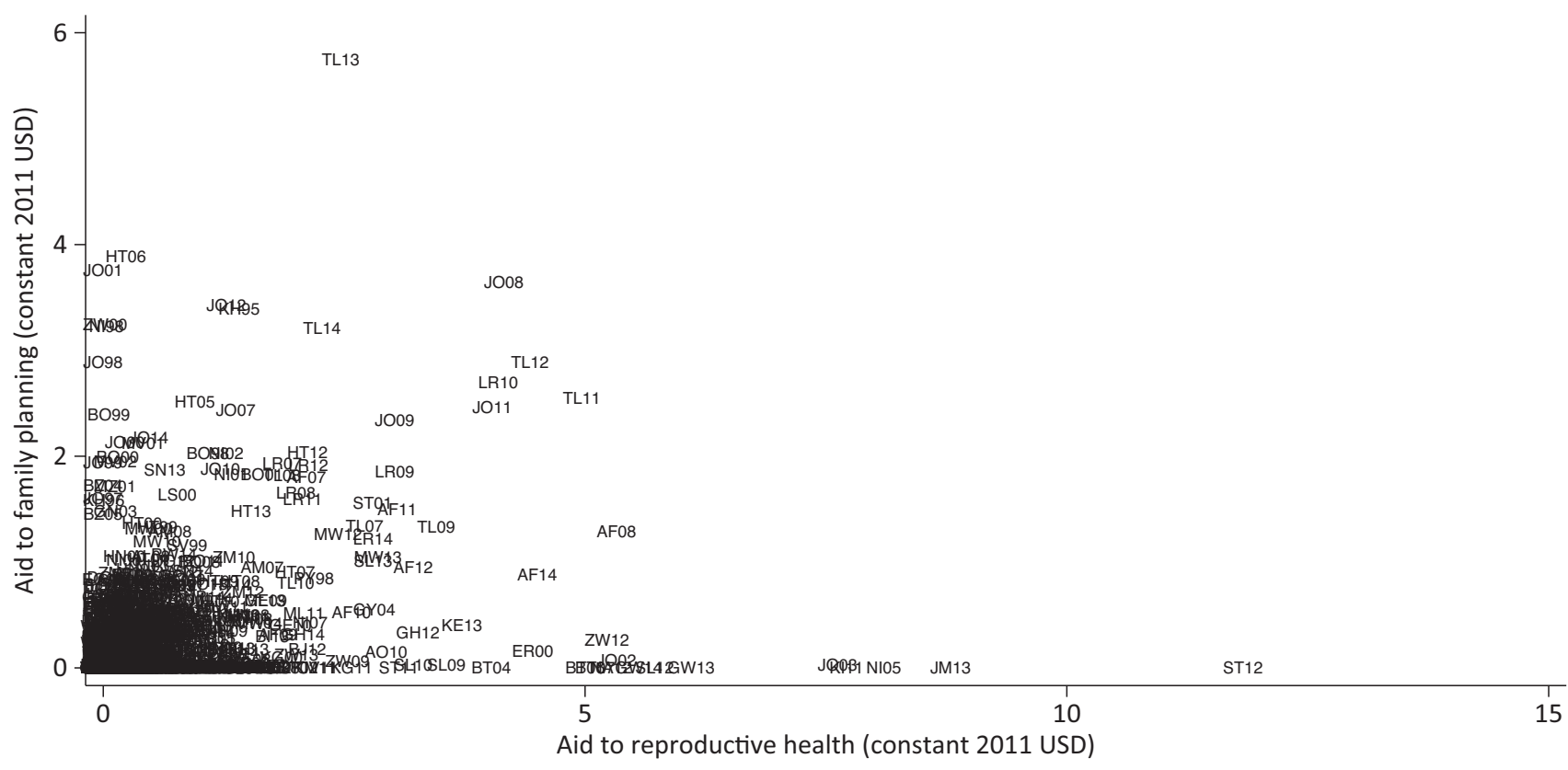

Figure 5. Scatterplot of per capita family planning vs. reproductive health-related aid, sample countries 1996-2014. 
even and at times inconsistent uptake of the most effective contraceptive methods, erosion of donor and government support for family planning, and the reallocation of funds towards HIV/AIDS programming are all factors in the reduced efficacy of family planning programs in recent years. Given these challenges, it is not, perhaps, surprising that our results reveal an association between family planning aid that is inconsistent. If family planning programs are increasingly limited, have less political support, and are being sidetracked by resources reallocated to other priorities, it is not unimaginable that they might not reduce maternal mortality.

In contrast to the narrower focus of reproductive health aid and aid to maternal health, our main analysis shows that total aid has no statistically significant effect on maternal mortality once other factors are controlled for. This may be due to the fact that the entirety of a country's ODA is expansive, and the amount allocated for maternal health is marginal. This is clear in our sample, where the mean level of total aid was $\$ 68.66$ per capita, while mean aid focused on reproductive health amounted to only slightly less than half a percent of that amount at $\$ 0.34$ per capita. It is not surprising, then, that total aid might not contribute directly to reductions in maternal mortality. Indeed, as has been indicated in much research, MMRs tend not to influence the amount of aid that is allocated to the health sector, whereas, in the case of HIV/AIDS, prevalence rates are closely linked to the amount of foreign funding for HIV/AIDS programs (Shiffman, 2006; Youde, 2010). It is as a result of the threat of the disease globally, which donors believe may be a threat to their own citizens and, therefore, to commit more resources to reduce the prevalence rates (Shiffman, 2006). A report from the OECD indicates that between 2006 and 2007, the amount of health-related aid allocated for HIV/AIDs programs constituted $39 \%$ as compared to $13 \%$ of aid allocated to the reproductive health sector (OECD, 2008). Maternal mortality may have seized the attention of the international aid community, but it is clear that, even with efforts like the Muskoka Initiative and the SDGs, funding perhaps does not yet match the development challenges posed by maternal mortality.

Our other results are in keeping with what is known about maternal mortality. Each factor shows the type of association with MMR that we would expect to see based on the research literature on maternal mortality. In our main analysis higher rates of adolescent fertility are associated with higher rates of maternal death. Likewise, our findings show that increasing access to modern methods of contraception reduces maternal mortality. The results of this study are consistent with Ahmed, Li, Liu and Tsui (2012) study which found that increased access to contraception in countries with low prevalence of contraceptive use averted 272,040 maternal deaths. This is because people can make choices regarding their reproductive health issues and will also avoid unintended pregnancies and to space the number of children they have.
Women with high parity are more likely to have high maternal mortality as compared to women who have timed and spaced their children. In addition, contraceptives lower the risk of unwanted and unintended pregnancies which often lead to abortion, considered to be the leading cause of maternal mortality in most developed countries (Haddad \& Nour, 2009; Okonofua, 2006; Rosmans \& Graham, 2006). Despite our potentially contradictory finding regarding the impact of family planning related aid funds, the effects of birth control use suggest it may well remain important to ensure that donor assistance is channeled towards the provision of contraceptives as it is a substantial and effective strategy of reducing maternal mortality in developing countries. Cleland et al.'s (2006) argument that family planning receives more international priority within the context of the SDG post2015 might be worth heeding in this case.

\section{Conclusion}

Since total aid is overly broad, there is insufficient evidence to suggest that overall ODA levels lead to a reduction in maternal mortality. However, once aid is targeted at the health sector generally, and at reproductive health, population programming, and maternal health more specifically, there is likely to be accelerated progress towards the achievement of the SDG target for maternal mortality. Still, despite increased efforts under Muskoka, there is a need to increase more resources not only to the health sector but in a more targeted way towards maternal health. Our results show that, despite the potential inefficacy of family planningfocused aid programs, access to contraceptives has a significant effect on the reduction of maternal mortality. It would, therefore, be important to channel more donor assistance to the promotion of contraceptive use among women as it serves as a tool to empower them and to take decisions that influence their reproductive behavior.

One limitation of this study was that it only analyzed bilateral ODA from the DAC donors and did not capture multilateral aid or aid from other non-traditional donors such as the WHO, NGOs, private foundations, businesses, among others. By tracking the amount committed from these other donors, a clearer picture of the effects of donor assistance on maternal mortality might emerge. Future research should track the amount of resources from the other donors not reported by the DAC so that the true effect of foreign assistance on maternal health could be established. Research is also needed to do a comparison between the DAC and the non-traditional donors to compare the behavior of these groups of donors and their impact on maternal mortality.

A second limitation of this study is that it does a crosscountry analysis of donor funding to various countries and the results may not be in context for all countries. A possible extension of this study could focus on individual countries and the amount of donor assistance received respectively, with more attention paid to what 
services, expertise, and reforms aid money is actually funding. Likewise, multilevel models studying the maternal health outcomes of individuals nested in national contexts could help deepen our understanding of the effects of aid further. A detailed case study of individual country is necessary in order to establish a more nuanced picture of the effect of foreign aid on maternal mortality. Donor decisions on the level of maternal health assistance provided, the nature of those programs, and how they are implemented in individual countries likely vary widely and it would be important to treat each country as a unique case.

The results of this study should be interpreted with caution since the data on the DAC reporting system broken down at the sector level are commitments from the donor community rather than actual disbursements, so actual aid flows to each country might depart significantly from what donors committed. Still, given these data limitations, our study is one of the first to clarify the relationship between aid and maternal mortality over time, and makes a contribution to both the research literature on maternal mortality specifically, and to the literature on the effects of aid more generally.

The Muskoka Initiative in $\mathbf{2 0 1 0}$ drew significant donor attention to the issue of maternal mortality and encouraged an intensification of efforts towards supporting recipient countries in achieving MDG 5 and reducing the burden of maternal mortality. These efforts now continue under the SDG framework of the 2030 Agenda. Our results suggest that this international agenda-setting exercise is not without merit. Foreign aid narrowly focused on issues of reproductive and maternal health is strongly associated with declining maternal mortality. As the implementation of Agenda 2030 unfolds, these results suggest that the international community would do well to continue to invest its development assistance resources in ongoing efforts to counter maternal mortality wherever it remains a significant threat to women's lives.

\section{Acknowledgments}

This research was supported by Memorial University's Scholarship in the Arts funding as well as the Social Sciences and Humanities Research Council of Canada (Swiss; Grant \#435-2016-0841).

\section{Conflict of Interests}

The authors declare no conflict of interests.

\section{References}

Ahmed, S., Li, Q., Liu, L., \& Tsui, A. O. (2012). Maternal deaths averted by contraceptive use: An analysis of 172 countries. Lancet, 380(9837), 111-125.

Annen, K., \& Kosempel, S. (2009). Foreign aid, donor fragmentation, and economic growth. The B.E. Journal of Macroeconomics, 9(1), Article 33.
Arndt, C., Jones, S., \& Tarp, F. (2015). Assessing foreign aid's long-run contribution to growth and development. World Development, 69, 6-18.

Arregoces, L., Daly, F., Pitt, C., Hsu, J., Martinez-Alvarez, M., Greco, G., . . . Borghi, J. (2015). Countdown to 2015: Changes in official development assistance to reproductive, maternal, newborn, and child health, and assessment of progress between 2003 and 2012. Lancet Global Health, 3(7), e410-e421.

Bishai, D. M., Cohen, R., Alfonso, Y. N., Adam, T., Kuruvilla, S., \& Schweitzer, J. (2016). Factors contributing to maternal and child mortality reductions in 146 low- and middle-income countries between 1990 and 2010. PLOS ONE, 11(1), e0144908.

Bornschier, V., Chase-Dunn, C., \& Robinson, R. (1978). Cross-national evidence of the effects of foreign investment and aid on economic growth and inequality: A survey of findings and a reanalysis. American Journal of Sociology, 84(3), 651-683.

Bradshaw, Y. W., Noonan, R., Gash, L., \& Sershen, C. B. (1993). Borrowing against the future: Children and third world indebtedness. Social Forces, 71(3), 629-656.

Burguet, R., \& Soto, M. (2012). Measuring the child mortality impact of official aid for fighting infectious diseases, 2000-2010 (Working Paper, No. 616). Barcelona: Institute for Economic Analysis (CSIC) and Barcelona GSE.

Cleland, J., Bernstein, S., Ezeh, A., Faundes, A., Glasier, A., \& Innis, J. (2006). Family planning: The unfinished agenda. Lancet, 368(9549), 1810-1827.

Conde-Agudelo, A., Belizan, J. M., \& Lammers, C. (2005). Maternal-perinatal morbidity and mortality associated with adolescent pregnancy in Latin America: Cross-sectional study. American Journal of Obstetrics and Gynecology, 192(2), 342-349.

Dalgaard, C., Hansen, H., \& Tarp, F. (2004). On the empirics of foreign aid and growth. The Economic Journal, 114(469), F191-F216.

Doucouliagos, C., Hennessy, J., \& Mallick, D. (2019). Health aid, governance and infant mortality (Discussion Paper, No. 12166). Bonn: IZA Institute of Labor Economics.

Dreher, A., \& Langlotz, S. (2017). Aid and growth. New evidence using an excludable instrument (Discussion Paper, No. 635). Heidelberg: University of Heidelberg, Department of Economics.

Durbarry, R., Gemmel, N., \& Greenaway, D. (1998). New evidence on the impact of foreign aid on economic growth (Research Paper, No. 98/9). Nottingham: University of Nottingham, Centre for Research in Economic Development and International Trade.

Easterly, W. (2003). Can foreign aid buy growth? Journal of Economic Perspectives, 17(3), 23-48.

Easterly, W. (2006). The white man's burden. New York, NY: Penguin.

Ekanayake, E. M., Cookman, B., \& Chatrna, D. (2000). The effect of foreign aid on economic growth in develop- 
ing countries. Journal of International Business and Cultural Studies, 3, 1-13.

Greco, G., Powell-Jackson, T., Borghi, J., \& Mills, A. (2008). Countdown to 2015: Assessment of donor assistance to maternal, newborn, and child health between 2003 and 2006. Lancet, 371, 1268-1275.

Grollman, C., Arregoces, L., Martinez-Alvarez, M., Pitt, C., Powell-Jackson, T., Hsu, J., . . . Borghi, J. (2017). Developing a dataset to track aid for reproductive, maternal, newborn and child health, 2003-2013. Scientific data, 4(170038). https://doi.org/10.1038/sdata. 2017.38

Grown, C., Addison, T., \& Tarp, F. (2016). Aid for gender equality and development: Lessons and challenges. Journal of International Development, 28(3), 311-319.

Haddad, L. B., \& Nour, M. N. (2009). Unsafe abortion: Unnecessary maternal mortality. Reviews in Obstetrics Gynecology, 2(2), 122-126.

Hsu, J., Pitt, C., Greco, G., Berman, P., \& Mills, A. (2012). Countdown to 2015: Changes in official development assistance to maternal, newborn, and child health in 2009-10, and assessment of progress since 2003. Lancet, 380(9848), 1157-1168.

Institute for Health Metrics and Evaluation. (2011). Maternal mortality estimates and MDG 5 attainment by country 1990-2011. Seattle, WA: Institute for Health Metrics and Evaluation.

Institute for Health Metrics and Evaluation. (2018). Financing global health 2017: Funding universal health coverage and the unfinished HIV/AIDS agenda. Seattle, WA: Institute for Health Metrics and Evaluation.

Kotsadam, A., Østby, G., Rustad, S. A., Tollefsen, A. F., \& Urdal, H. (2018). Development aid and infant mortality. Micro-level evidence from Nigeria. World Development, 105(2018), 59-69.

Mishra, P., \& Newhouse, D. (2009). Does health aid matter? Journal of Health Economics, 28(4), 855-872.

Moyo, D. (2009). Dead aid: Why aid is not working and how there is a better way for Africa. New York, NY: Farrar, Straus and Giroux.

Nanda, G., Switlick, K., \& Lule, E. (2005). Accelerating progress towards achieving the MDG to improve maternal health: A collection of promising approaches (Discussion Paper, No. 31969). Washington, DC: The World Bank, Health, Nutrition and Population.

Nove, A., Mathews, Z., Neal, S., \& Camacho, A. V. (2014). Maternal mortality in adolescents compared with women of other ages: evidence from 144 countries. Lancet Global Health, 2(3), 155-164.

Okonofua, F. (2006). Abortion and maternal mortality in the developing world. Journal Obstetrics Gynaecology Canada, 28(11), 974-979.

Organization for Economic Cooperation and Development (OECD). (2008). Measuring health aid. Retrieved from http://www.oecd.org/investment/ stats/41453717.pdf

Pandolfelli, L. E., Shandra, J., \& Tyagi, J. (2014). The inter- national monetary fund, structural adjustment, and women's health: A cross-national analysis of maternal mortality in Sub-Saharan Africa. The Sociological Quarterly, 55(1), 119-142.

Pickbourn, L., \& Ndikumana, L. (2016). The impact of the sectoral allocation of foreign aid on gender inequality. Journal of International Development, 28(3), 396-411.

Powell-Johnson, T., Borghi, J., Mueller, D. H., Patouillard, E., \& Mills, A. (2006). Countdown to 2015: Tracking donor assistance to maternal, newborn, and child health. Lancet, 368(9541), 1077-1087.

Proulx, K. R., Ruckert, A., \& Labonté, R. (2017). Canada's flagship development priority: Maternal, newborn and child health (MNCH) and the Sustainable Development Goals (SDGs). Canadian Journal of Development Studies, 38(1), 39-53.

Rosmans, C., \& Graham, W. (2006). Maternal mortality: Who, when, where, and why. Lancet, 368(9542), 1189-1200.

Sell, R., \& Kunitz, S. (1986). The debt crisis and the end of an era in mortality decline. Studies in Comparative International Development, 21, 3-30.

Shen, C., \& Williamson, J. B. (1999). Maternal mortality, women's status, and economic dependency in less developed countries: A cross-national analysis. Social Science \& Medicine, 49(2), 197-214.

Shiffman, J. (2006). HIV/AIDS and the rest of the global health agenda. Bulletin of the World Health Organization, 84(12), 923.

Taylor, E. M., Hayman, R., Crawford, F., Jeffery, P., \& Smith, J. (2013). The impact of official development aid on maternal and reproductive health outcomes: $A$ systematic review. PLOS ONE, 8(2), e56271. https:// doi.org/10.1371/journal.pone.0056271

Tilburg, C. V. (2015). Controversies in medical aid to developing countries: Balancing help and harm. International Health, 7(3), 147-148.

Thomson, M., Kentikelenis, A., \& Stubbs, T. (2017). Structural adjustment programmes adversely affect vulnerable populations: A systematic-narrative review of their effect on child and maternal health. Public Health Reviews, 38(13). https://doi.org/10.1186/ s40985-017-0059-2

Tiessen, R. (2015). 'Walking wombs': Making sense of the Muskoka initiative and the emphasis on motherhood in Canadian foreign policy. Global Justice: Theory Practice Rhetoric, 8(1), 76-93.

Williamson, R. C. (2008). Foreign aid and human development: The impact of foreign aid to the health sector. Southern Economic Journal, 75(1), 188-207.

Winkleman, T. F., \& Adams, G. B. (2017). An empirical assessment of the relationship between official development aid and child mortality, 2000-2015. International Journal of Public Health, 62(2), 231-240.

Winters, M. S. (2010). Accountability, participation and foreign aid effectiveness. International Studies Review, 12(2), 218-243. 
World Health Organization, International Confederation of Midwives, \& International Federation of Gynecology and Obstetrics. (2004). Making pregnancy safer: The critical role of the skilled attendant. Geneva: World Health Organization.

World Health Organization. (2011). International statistical classification of diseases and related health problems (Vol. 2). Geneva: World Health Organization.

World Health Organization. (2018). Adolescent pregnancy. World Health Organization. Retrieved from https://www.who.int/news-room/fact-sheets/ detail/adolescent-pregnancy

World Health Organization, UNICEF, UNFPA, \& The World
Bank. (2012). Trends in maternal mortality: 1990 to 2010. Geneva: World Health Organization.

World Health Organization, UNICEF, UNFPA, \& The World Bank. (2015). Trends in maternal mortality: 1990 to 2015. Geneva: World Health Organization.

Yogo, U. T., \& Mallaye, D. (2015). Health aid and health improvement in Sub-Saharan Africa: Accounting for the heterogeneity between stable states and postconflict states. Journal of International Development, 27(7), 1178-1196.

Youde, J. (2010). The relationships between foreign aid, HIV and government health spending. Health Policy and Planning, 25(6), 523-528.

\section{About the Authors}

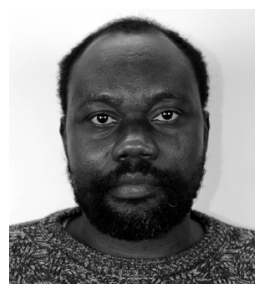

Emmanuel Banchani is a PhD Candidate in Sociology at Memorial University of Newfoundland. His research interests center on maternal and child health issues, women's health, chronic diseases, health and aging in sub-Saharan Africa.

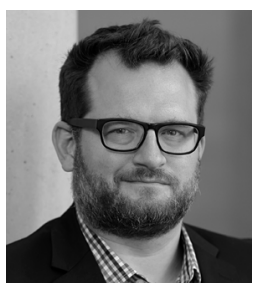

Liam Swiss is Associate Professor of Sociology at Memorial University of Newfoundland. His current research examines the role of foreign aid in international norm diffusion, violence against aid workers, the politics of Canadian aid policy, and the causes and effects of women's political representation in the Global South. His research has appeared in journals such as the American Sociological Review, Social Forces, Social Science Research, and World Development. His book The Globalization of Foreign Aid: Developing Consensus was published by Routledge in 2018. 


\section{Appendix}

Table A1. Instrumental variable two-stage fixed effects regression of maternal mortality on foreign aid, $1996-2014$.

\begin{tabular}{|c|c|c|c|c|c|c|}
\hline & (1) & $(2)$ & (3) & (4) & (5) & (6) \\
\hline \multicolumn{7}{|c|}{ Second stage regression results (two-way fe) } \\
\hline \multicolumn{7}{|l|}{ Aid measures (logged) } \\
\hline Total aid & -4.41 & & & & & \\
\hline Total aid to health & & $-54.28 * *$ & & & & \\
\hline Aid to reproductive health & & & $-104.97 * * *$ & & & \\
\hline Aid to family planning & & & & -10.08 & & \\
\hline Total aid to population/reproductive policy & & & & \multicolumn{3}{|c|}{$-54.73 * * *$} \\
\hline Total MNH Aid (ODA plus dataset) & & & & & & $-76.65 * * *$ \\
\hline Observations & 2054 & 2054 & 2054 & 2054 & 2054 & 2054 \\
\hline Countries & 128 & 128 & 128 & 128 & 128 & 128 \\
\hline R-Squared & 0.50 & 0.30 & 0.39 & 0.51 & 0.42 & 0.49 \\
\hline Controls & yes & yes & yes & yes & yes & yes \\
\hline Country FE & yes & yes & yes & yes & yes & yes \\
\hline Year FE & yes & yes & yes & yes & yes & yes \\
\hline Cragg-Donald Weak Identification & 617.45 & 24.72 & 79.90 & 334.66 & 164.92 & 609.00 \\
\hline Anderson Underidentification Test & 471.83 & 24.69 & 77.60 & 288.05 & 153.60 & 466.93 \\
\hline
\end{tabular}

\begin{tabular}{|c|c|c|c|c|c|c|}
\hline \multicolumn{7}{|c|}{ First stage regression results (two-way fe) } \\
\hline Fitted aid (correspond to aid measures above) & $0.52 * * *$ & $0.15^{* * *}$ & $0.34 * * *$ & $0.54 * * *$ & $0.34 * * *$ & $0.68 * * *$ \\
\hline Observations & 2054 & 2054 & 2054 & 2054 & 2054 & 2054 \\
\hline Countries & 128 & 128 & 128 & 128 & 128 & 128 \\
\hline R-Squared & 0.30 & 0.10 & 0.13 & 0.23 & 0.29 & 0.60 \\
\hline Controls & yes & yes & yes & yes & yes & yes \\
\hline Country FE & yes & yes & yes & yes & yes & yes \\
\hline Year FE & yes & yes & yes & yes & yes & yes \\
\hline \multicolumn{7}{|c|}{ Zero order regression results (OLS) } \\
\hline One-year lagged aid measure & $0.93 * * *$ & $0.73 * * *$ & $0.59 * * *$ & $0.67 * * *$ & $0.81 * * *$ & $0.76 * * *$ \\
\hline Donor fractionalization-aid receipt probability & $0.58 * *$ & $0.89 * * *$ & $0.44 * * *$ & $0.28 * * *$ & $0.69 * * *$ & 0.10 \\
\hline Observations & 2054 & 2054 & 2054 & 2054 & 2054 & 2054 \\
\hline Countries & 128 & 128 & 128 & 128 & 128 & 128 \\
\hline R-Squared & 0.88 & 0.54 & 0.36 & 0.48 & 0.65 & 0.59 \\
\hline Controls & no & no & no & no & no & no \\
\hline Country FE & no & no & no & no & no & no \\
\hline Year FE & no & no & no & no & no & no \\
\hline
\end{tabular}

Notes: ${ }^{*} \mathrm{p}<0.05,{ }^{* *} \mathrm{p}<0.01,{ }^{* * *} \mathrm{p}<0.001$. The donor fractionalization-aid receipt probability measures in the zero order regression is the interaction of the mean donor-state government fractionalization (World Bank DPI) for all donors in a given recipient country and the mean probability of a recipient country to receive any aid from all possible donors in the Swiss and Longhofer (2016) dataset. The interaction term is lagged five years to account for the aid project cycle, providing time for changes in donor governments and aid levels to take effect. 
Table A2. Two-way fixed effects panel regression of maternal mortality on five-year average foreign aid flows, 1999-2015.

(1)

(2)

(3)

(4)

(5)

(6)

Aid measures (logged five-year average)

Total aid

Total aid to health

Aid to reproductive health

Aid to family planning

Total aid to population/reproductive policy

Total MNH Aid (ODA plus dataset)

$$
-6.54 * *
$$

$-18.09 * * *$

Observations

Countries

R-Squared

Controls

Country FE

Year FE

\begin{tabular}{|c|c|c|c|c|c|}
\hline & $-18.09^{*}$ & $-47.97^{* * *}$ & $-17.96^{*}$ & $-27.04 * * *$ & $-45.58^{* * *}$ \\
\hline 919 & 1919 & 1919 & 1919 & 1919 & 1919 \\
\hline 130 & 130 & 130 & 130 & 130 & 130 \\
\hline 0.68 & 0.68 & 0.67 & 0.68 & 0.66 & 0.68 \\
\hline yes & yes & yes & yes & yes & yes \\
\hline yes & yes & yes & yes & yes & yes \\
\hline yes & yes & yes & yes & yes & yes \\
\hline
\end{tabular}

Notes: ${ }^{*} p<0.05,{ }^{* *} p<0.01,{ }^{* * *} p<0.001$.

Table A3. Two-way fixed effects panel regression of maternal mortality on foreign aid, different lags.

\begin{tabular}{lccccc}
\hline & $(1)$ & $(2)$ & $(3)$ & $(4)$ & $(5)$ \\
& 1-year lag & 2-year lag & $\begin{array}{c}\text { 3-year lag } \\
\text { 4-year lag }\end{array}$ & \begin{tabular}{c} 
5-year lag \\
\hline Aid measures (logged)
\end{tabular} \\
Total aid & -1.34 & -1.85 & -1.85 & -1.83 & -1.57 \\
Total aid to health & $-7.12^{* * *}$ & $-5.37^{* * *}$ & $-5.52^{* * *}$ & $-5.59^{* * *}$ & $-4.65^{* * *}$ \\
Aid to reproductive health & $-26.07^{* * *}$ & $-23.78^{* * *}$ & $-21.58^{* * *}$ & $-17.42^{* * *}$ & $-17.10^{* * *}$ \\
Aid to family planning & $-13.10^{*}$ & $-9.76^{*}$ & -2.82 & -0.24 & 3.12 \\
Total aid to population/reproductive policy & $-16.41^{* * *}$ & $-16.72^{* * *}$ & $-16.25^{* * *}$ & $-15.44^{* * *}$ & $-14.90^{* * *}$ \\
Total MNH Aid (ODA plus dataset) & $-33.46^{* * *}$ & $-38.67^{* * *}$ & $-35.04^{* * *}$ & $-30.73^{* * *}$ & $-26.81^{* * *}$ \\
\hline Observations & 2093 & 1965 & 1837 & 1709 & 1582 \\
Countries & 130 & 130 & 130 & 128 & 127 \\
Controls & yes & yes & yes & yes & yes \\
Country FE & yes & yes & yes & yes & yes \\
Year FE & yes & yes & yes & yes & yes \\
\hline
\end{tabular}

Notes: ${ }^{*} p<0.05,{ }^{* * *} p<0.001$

Table A4. Two-way fixed effects panel regression of MMR on foreign aid, 1996-2011, (IHME MMR measure).
(1)
(2)
(3)
(4)
(5)
(6)

\section{Aid measures (logged)}

Total aid

$-13.79 * * *$

Total aid to health

Aid to reproductive health

Aid to family planning

Total aid to population/reproductive policy

Total MNH Aid (ODA plus dataset)

$$
-13.64^{* * *}-28.30^{* * *}
$$

3.33

\begin{tabular}{lcccccc}
\hline Observations & 1582 & 1582 & 1582 & 1582 & 1582 & 1582 \\
Countries & 127 & 127 & 127 & 127 & 127 & 127 \\
R-Squared & 0.06 & 0.11 & 0.07 & 0.11 & 0.02 & 0.08 \\
Controls & yes & yes & yes & yes & yes & yes \\
Country FE & yes & yes & yes & yes & yes & yes \\
Year FE & yes & yes & yes & yes & yes & yes \\
\hline
\end{tabular}

Notes: ${ }^{* *} p<0.01,{ }^{* * *} p<0.001$. 


\section{Reference}

Swiss, L., \& Longhofer, W. (2016). Membership has its privileges: Shared international organizational affiliation and foreign aid flows, 1978-2010. Social Forces, 94(4), 1769-1793. 